\title{
Using Index model and Markowitz Model to analyze the Results of Retail Industries Before and After the Covid-19 Virus Outbroke
}

\author{
Changjie Chen* \\ School of Liaoling University, Shengyang,China \\ ${ }^{*}$ Corresponding author: Guanghua.ren@gecacademy.cn
}

\begin{abstract}
Since covid-19 outbroke in January 1st ,2020, many disasters happened in these two years, for example medical resources are in short supply for every patient. All those disasters caused chaos in all over the world, so caused investors lost confidence in financial market. The prices of stocks were dropped so rapidly, almost all markets influenced by covid-19 virus. This paper will focus on retail industries which have close connection with consumers lives, anyone cannot live without them. People still have faith in retail industries, but still these industries had impact from covid- 19 . To compare the changes of retail industries before covid-19 virus with after covid-19 virus, I used Index model and Markowitz Model computed their results, stand deviation and Maximum Sharpe ratio. From the results, it is no hard to tell risk of retail industries were small, their standard deviations all between $0 \%$ to $15 \%$ no matter before or after covid-19 virus, which can help investors strengthen confidence and did not lost money. In conclusion, if retail industries can complete transformation, they only be impacted by a short time and become great portfolio for investors.
\end{abstract}

Keywords: covid-19, retail industry, Index model, Markowitz Model

\section{Introduction}

It has been two years since covid-19 been brought out from January 1st ,2020, and many disasters happened in these two years, natural calamities, medical resources are in short supply for every patient, also included financial market turmoil. The covid-19 outbreak is not only a short-term impact, but also a long-term test [1]. Because covid-19 is a disease has a very strong infectivity when people have a face to face communication, so each countries government and The Committee of the United Nations Health Organize just suggested all of us stay at home instead of having party outside or gathering around. This major public emergency, which endangers public health and the lives of ordinary people and medical staff, is not only a big test of the public health emergency management ability and emergency response system around the world, but also a severe test of the financial market [1].

Economist also predicted that the impact of covid-19 will still last and expend for a very long time. But it was true that the covid-19 had a quite bad influence of financial market, it was obvious from historical data. Since March in 2020, the financial market of America was closed for the fourth consecutive circuit breaker. America consecutive circuit breaker mechanism is based on a series of price fluctuation restrictions of the reference price, generally it is according to the SPX500 index. The first threshold is declined for 7\%, then the hole USA financial market will stop trading for 15 minutes. If this index keeps falling for $20 \%$, then the USA financial market still will stop trading for 15 minutes. But if the index goes down to the third threshold, then the deal will be cancelled at that day. Unfortunately, just because covid-19 outbroke in 2020 and did a very bad influence on the whole world, all the USA financial market just showed chaos, being like a disaster. Even Mr. Buffett, a famous investor, thought that he lived eighty-nine years, for the first time to experience such a big change. And almost all countries financial market in the world had touch the circuit breaker in a row. Each country had to produce a series of policies to limit virus expend were also limited the foreground of financial market. So, the beginning of 2020 was quite a important turning point. Retail industries also in financial market, but compared to other market, they have closer relationship with consumers, and related to the national economy. Under the epidemic, national traffic control and delayed 
resumption of work have been introduced to restrict the flow of people and outbound consumption. The buyers of retail industries are basically zero, so the retail industries is almost suspended. Supermarkets and community stores have been closed, and the retail industry closely related to people's lives has been severely damaged [2].

To find a way solve the problem of covid-19 strong infectivity, reduce human face to face contact. So, the retail industries have been seeing persistent transformation, self-service stores, become a new form of business. For example, Amazon Go had already been the first retail industry tried the new trading way. Amazon Go, which has open two stores in Seattle, USA, and cy, which also operates 12 supermarkets in Utah, allows supermarket consumers to checkout directly with bar codes through mobile applications. Easy checkout that saves consumers time and effort seems to have become a trend in U. S. retail since covid-19 outbroke [3]. However, back in 2018, Kroger had implemented the plan. But in that time, people did not pay a lot of attention in it. Nowadays, covid-19 had changed this new trading, and redefined it. Every store highlighted self-service stores are clean and safety, and won many consumers favors.

What's more, due to the epidemic, consumers have limited their scope of activities, so more consumers prefer to complete buying goods online rather than choose to buy in offline stores for security reasons [4]. Take America fresh E-commerce to be an example. In the past, the retail channels of fresh goods had been mainly offline, and people prefer to choose and purchase them offline rather than the requirements of product freshness. However, the arrival of the epidemic has forced the elderly to choose online shopping, and on the other hand, it has met the needs of young people to buy food and cook at home without leaving home. This makes the demand for existing fresh e-commerce platforms greatly increased, some scholar's statistics found that during the Spring Festival in 2020, the sales of major fresh e-commerce companies have soared [4]. But fresh products are not easy to store, so the fresh electricity supply chain ability put forward to high requirements. So, to improve the supply chain, the online retail channels combined with the main retail concept is to strengthen the distribution capacity. After online trading, customers want to deliver the goods as soon as possible. The time from placing an order to receive the goods affects the customer's shopping experience. Therefore, it is needed to strengthen the distribution capacity and to ensure the distribution speed [5].

Also, covid-19 is a virus and can let person get cough. Sometimes if the patient had bad physical quality, the covid-19 virus even cause death. In this case, so many death examples had caught people in the world pay attention to their body quality. And how to shape a good body quality, the first step is to build a good eating habit. COKE is a retail industry sell snacks for hundreds of years, but snake is so easy to lead corpulent. Obesity correlates with increased risk foy hypertension, even heart attack. Finally, bad eating habits lead in a decrease in body immunity, so the covid-19 virus swept in patient body easily. Maybe this is a reason why COKE had a huge drop sales volume since covid-19 existed. What would COKE do to turn the table? The drink has been facing health controversy in recent years. Over the last few years, the company that started selling "sugar water" 130 years ago has introduced the concept of "sugar reduction" into its product line to meet consumer demand for a healthier lifestyle. James Quincey, chairman and CEO of Coca-Cola recognized the operating model adjustment will change how retail industries market and bring their execution closer to customers. At the same time, retail industries will gather to develop those strong brands and pursue innovative strategies. While advancing these changes, they are also constantly optimizing the organizational structure, including important adjustments to the team structure. Single-box sales of the Coca-Cola brand rose $1 \%$ in the quarter, while zero-sugar Coca-Cola sales rose $7 \%$ in the quarter [6].

Fortunately, although covid-19 limited consumers shopping, but also customers have more time to surf the internet. It is the right time for retail industries put advertisement on the internet, to expand their brand reputation in a good way. Nestle, as an international food giant, it launched some topics on Weibo to pay tribute to the ordinary people who tried to maintain the normal operation of society during the epidemic period, and advocated "good food and good life", and conveyed a positive attitude to life, which are both warm heart and close to consumer lives. Once the idea of "good food and good life" was issued, it quickly responded by nearly 200 brands, including Unilever, and other 
international giant brands. The reason why Nestle's action has received such a great response is because it concerned its consumers, had a good communication with them, also build a new and loyalty relationship with consumers. Compared with the other major brands advertisement during the epidemic, Nestle just doing the right thing at the right time [7].

Except food retail industries, what about other retail industries which to produce daily product, like make-up retail industries? Performance reports released by several global consumer goods giants show that the novel coronavirus is quietly changing people's lifestyle: consumers spend more time for cooking and cleaning, and less time spending on dressing or decking oneself out [8]. Unilever has released a comprehensive performance report on the impact of the epidemic on global consumers. CFO Graeme said instant soup cubes, and instant noodles are in increasing demand as people cook more and more at home. However, people use personal care products such as shampoo and body dew increasingly frequently, with an estimated $11 \%$ less weekly consumption. It seems like consumers have a longer-term pursuit, and focus on health, hygiene, and cleaning consumption habits lifestyle. Covid-19 virus had already changed shopping list of consumers, if make-up retail industries like LRLCY could produce a new channel for "cooking fast at home" could help the quantity of sale during covid-19. UL is a retail industry concerned of cleaning product, unlike LRLCY, as the reasons we mentioned before, UL had a steady quantity of sailing. UL had a very strong charging power with its suppliers as usual, because it had 66 billion of dollars mobility cash flow while other companies were nearly going bankrupt [9].

In a word, it is right time for different retail industries changing and completing transformation in various ways. In the special period of inconvenience for consumers to go out shopping, instant delivery shows great advantages and importance. The e-commerce platforms cooperate with offline stores and socialized logistics to cut into the instant consumer market. Through the comprehensive application of intelligent technology, "retail + distribution" mode is realized with different transport capacity modes to meet people's diversified needs in different periods [10]. But Literatures about retail industries hadn't have specific data to compare changes before covid-19 and after covid-19. To improve this deficiency, next step I will do is to select couples of retail industries in different types, and analysis them by using Index module and Markowitz Model. It is not hard to tell if retail industries finally find a way suitable for their transformation, covid-19 virus only bought short time dropped of quantity of sailing. Luckily, from the price chart, the giant retail industries I chose seems had a quick reaction to face the challenges that covid-19 bought. And Index model and Markowitz Model showed if we choose retail industries to be investment portfolio could be a good choice. Cause the data remained steady, means retail industries had little return but less risk than other industries. In a turbulent social environment, steady portfolios can help investors do not lost their money and strengthen investors' confidence of financial market.

\section{Data}

The COVID-19 outbreak in early 2020 continues to spread around the world, casting a thick shadow over global economic growth. Because covid-19 is a disease has a very strong infectivity when people have a face-to-face communication, so each countries government and The Committee of the United Nations Health Organize just suggested all of us stay at home instead of having party outside or gathering around. In order to cope with the spread of the epidemic, countries have taken measures such as "city closure", shutdown the worker to produce and quarantine and so on. In this way, It is a really useful method to help our earth to prevent the further spread of covid-19. But unfortunately, this method also causes a lots of problem. Because retail industries had no worker to product, international trade has shrunk severely, even lots of retail industries had been went bankrupt. And frequent "black swan" incidents not only have occurred in the retail industries, but also happened in international financial markets. So in this paper, I am going to investigate how to form an optimal portfolio based on the selected stocks. 
First of all, I have chosen prices data from Yahoo finance for last decades respectively from spx500 and retail industries, which include Pepsi (PEP), Coca-Cola (COKE), Nestle (NSRCY), Unilever (UL), Lancôme (LRLCY). Then, I separated them into two ways. Because covid-19 has brought out in 2020.1.1, so i chose 2020.1.1 to be selected node. One of prices data are from 2009.9.25 to 2020.1.1, and I recognized them to be the prices before covid-19; another one are from 2020.1.1 to 2021.9.25, and I recognized them to be the prices during covid-19.

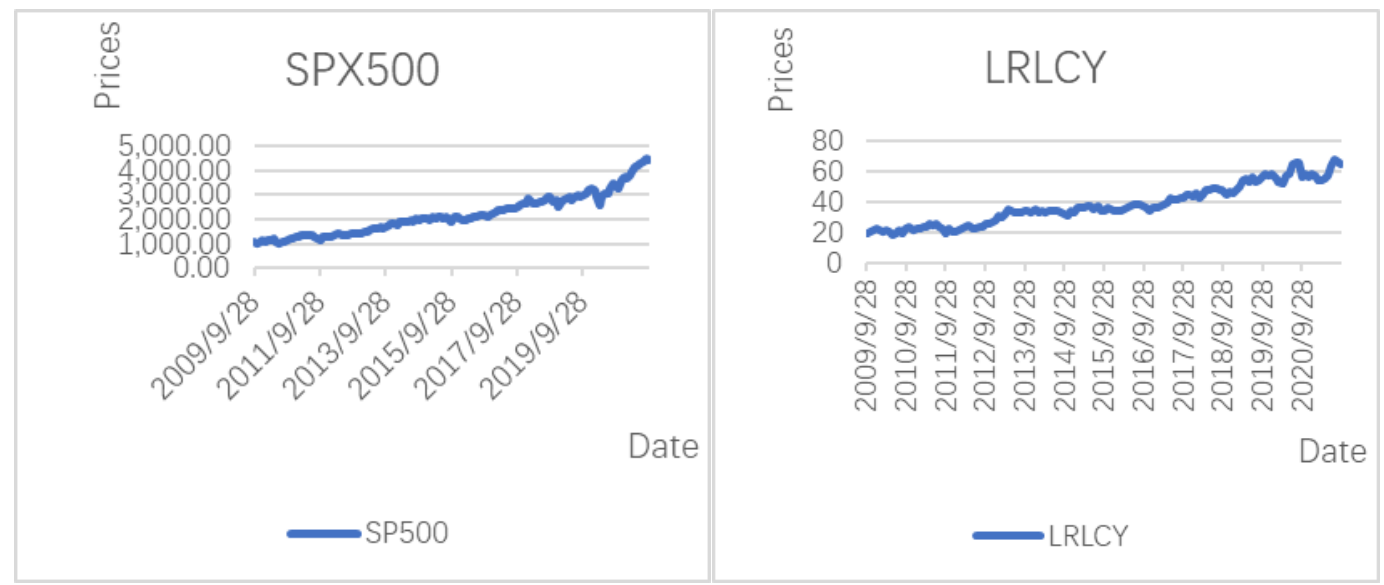

(a)

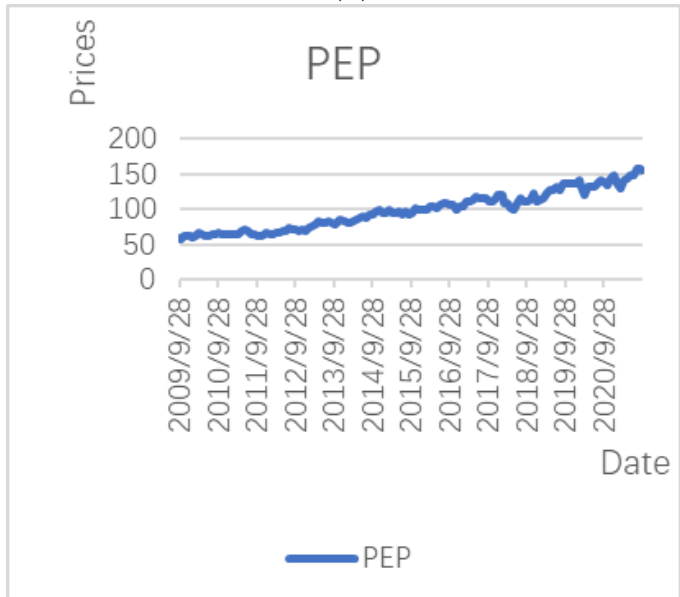

(c)

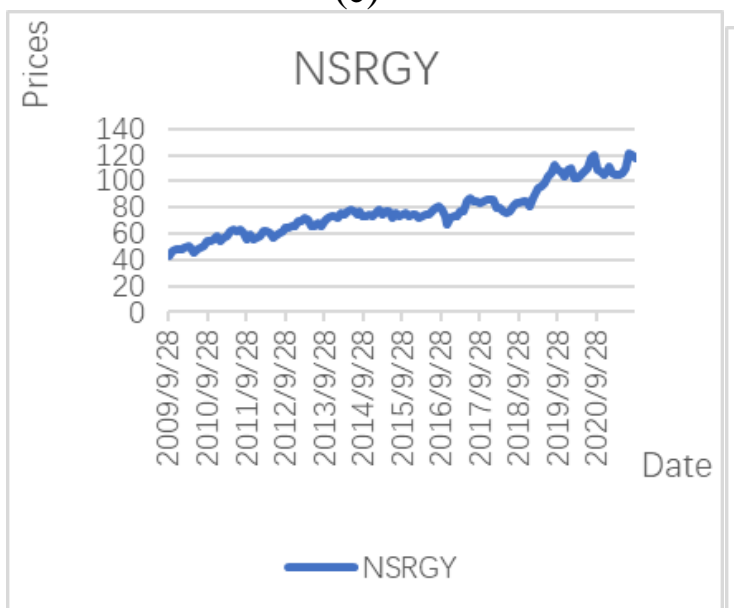

(e)

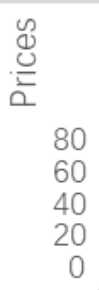

(b)

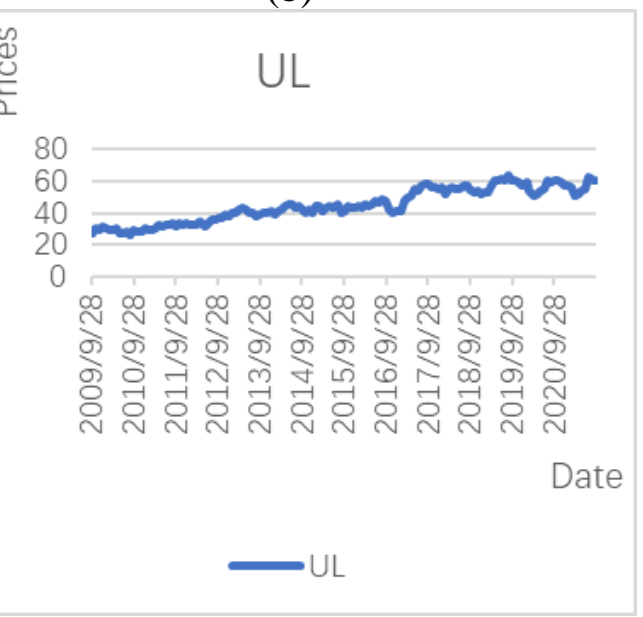

(d)

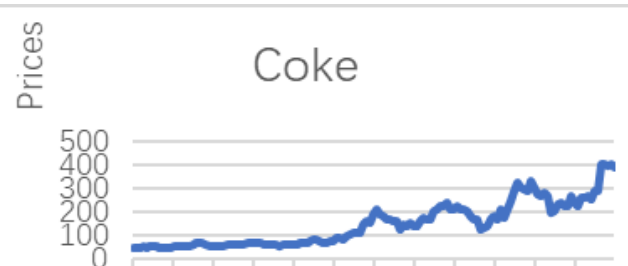

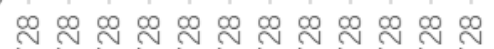

के के के के के के के के के के

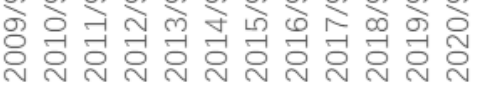

Date

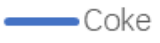

(f)

Figure 1. Stock prices for the selected stocks and SPX. (a)SPX500 (b)LRLCY (c)PEP (d)UL (e)NSRGY (f)COKE

Source: Yahoo Finance. 


\section{Source: Yahoo Finance}

From the prices chart of SPX500, we can tell the financial market always had gradually rise for last decades. The period from 2009 to 2016 saw an upward trend in the prices of SPX500 from $\$ 1000$ approximately to $\$ 2000$, then there was a sharply increase in the prices of SPX500 from $\$ 2000$ in 2016 to $\$ 3500$ in 2019.However, at the end of 2019, in the beginning of 2020, The prices of SPX500 rapidly dipped from $\$ 3500$ to $\$ 2500$. That was a time when covid-19 had break out and result in the fall down trend of financial market. Another retail industry had the same trend was COKE. From the prices chart of COKE, it is not hard to tell COKE prices used to be grew steadily before 2015, but suddenly, COKE prices had several dramatically fluctuated. There was a rapidly increase in the prices of COKE from $\$ 100$ in 2015 but reached the peak of $\$ 350$.It was almost increasing three and a half times since 2015. But like the trend of SPX500, the prices of COKE had rapidly drop from $\$ 350$ in the end of 2019 to $\$ 200$.Then it had sharply jumped again and reached the highest point against of $\$ 400$. It is such a huge jump.

But another four retail industries I chose did not have such a big change from last decades. PEP is the drinking retail industries just like COKE, but the two retail industries have so many in commons did not share the same prices change. The prices of PEP were unlike COKE, it didn't have such a huge jump from the bottom to the top. PEP prices had steadily soared, an upward trend was seen in the prices of PEP from $\$ 60$ in 2009 to $\$ 160$ in 2021. Another retail industry also is a drinking retail industry is NSRGY. NRLSY also sold drinks and showed in public as a food company, but the most special characteristic is that it sold most convenient food. Like the hand make coffee, hand make tea and so on. The prices of NSRGY just like PEP prices, had a gradually shoot up, From the NSRGY prices chart, the prices of NSRGY increased slightly from $\$ 40$ in 2009 to $\$ 120$ in 2021. Another two companies, UL and LRLCY, they also are retail industries too. But different with COKE, PEP and NSCRCY, they didn't sell food. Instead, they sold Stuffs you can use in daily life. But UL more concerned of daily clean part, like soap, laundry detergent, while LRLCY are more concerned about makeups and skin creams. Compared their prices chart, we found lots in common: Both had steadily surge trend, and less fluctuation like COKE and SPX500. UL prices remained much more stable than LRLCY, and there was a little change in the prices of UL from $\$ 30$ in 2009 to $\$ 60$ in 2021, a slightly soared in the prices of LRLCY from \$20 in 2009 and \$70 in 2021.

It seems like covid-19 did not have impact on these retail industries except COKE.

Then I computed their correlation by using their return.

Table 1: This is a table of the correlation for the selected stocks before and after covid 19.

TABLE 1. THE ARRANGEMENT OF CHANNELS

\begin{tabular}{ccccccc}
\hline \hline Before & SPX & LRLCY & NSRGY & PEP & UL & Coke \\
\hline SPX & $100 \%$ & $57 \%$ & $40 \%$ & $44 \%$ & $43 \%$ & $26 \%$ \\
LRLCY & $57 \%$ & $100 \%$ & $58 \%$ & $42 \%$ & $65 \%$ & $20 \%$ \\
NSRGY & $40 \%$ & $58 \%$ & $100 \%$ & $49 \%$ & $59 \%$ & $28 \%$ \\
PEP & $44 \%$ & $42 \%$ & $49 \%$ & $100 \%$ & $51 \%$ & $31 \%$ \\
UL & $43 \%$ & $65 \%$ & $59 \%$ & $51 \%$ & $100 \%$ & $24 \%$ \\
Coke & $26 \%$ & $20 \%$ & $28 \%$ & $31 \%$ & $24 \%$ & $100 \%$ \\
& & & & & & \\
After & SPX & LRLCY & NSRGY & PEP & UL & Coke \\
SP500 & $100 \%$ & $31 \%$ & $44 \%$ & $69 \%$ & $41 \%$ & $52 \%$ \\
LRLCY & $31 \%$ & $100 \%$ & $76 \%$ & $25 \%$ & $43 \%$ & $27 \%$ \\
NSRGY & $44 \%$ & $76 \%$ & $100 \%$ & $30 \%$ & $69 \%$ & $15 \%$ \\
PEP & $69 \%$ & $25 \%$ & $30 \%$ & $100 \%$ & $20 \%$ & $48 \%$ \\
UL & $41 \%$ & $43 \%$ & $69 \%$ & $20 \%$ & $100 \%$ & $6 \%$ \\
Coke & $52 \%$ & $27 \%$ & $15 \%$ & $48 \%$ & $6 \%$ & $100 \%$ \\
\hline \hline
\end{tabular}


Before 2020.1.1, when covid-19 haven't been brought out, each of them had a great correlation. SPX500 had the greatest correlation with LRLCY was 57.08\%, had the lowest correlation with COKE only $26.19 \%$. While during covid-19, SPX500 had the greatest correlation with PEP was $68.51 \%$, had the lowest correlation LRLCY only 31.5\%. And during covid-19 SPX500 and COKE had 51.5\% correlation, more than a half. Before the covid-19, UL and LRLCY had best correlation for 65.19\%, but during covid-19, NSRGY and LRLCY had the best correlation for 75.91\%. Before the covid-19, COKE and LRLCY had lowest correlation for $19.51 \%$, but during covid-19, COKE and UL had the lowest correlation for $5.88 \%$. Math

\section{Model}

In this paper, the portfolio is formed as:

Portfolio StDev=

$$
\begin{aligned}
& \text { weight }_{\text {spx500 }} \times \text { Annualled StDex }_{\text {spx } 500+\text { weight }_{\text {LRLCY }} \times \text { Annualled StDex }_{\mathrm{LRLCY}}} \\
&+ \text { weight }_{\mathrm{NSRGY}} \times \text { Annualled StDex }_{\mathrm{NSRGY}}+\text { weight }_{\mathrm{PEP}} \times \text { Annualled StDex }_{\mathrm{PEP}} \\
&+ \text { weight }_{\mathrm{UL}} \times \text { Annualled StDex } \\
& \mathrm{UL}+ \text { weight }_{\mathrm{COKE}} \times \text { Annualled StDex }_{\mathrm{COKE}} \\
& \text { Portfolio Maximum Sharpe ratio }
\end{aligned}
$$

$$
\begin{aligned}
& =\left(\text { weight }_{\mathrm{spx} 500} \times \text { Annaliued Average Return }_{\mathrm{spx} 500}\right. \\
& + \text { weight }_{\mathrm{LRLCY}} \times \text { Annaliued Average Return }_{\mathrm{LRLCY}} \\
& + \text { weight }_{\mathrm{NSRGY}} \times \text { Annaliued Average Return } \\
& \mathrm{NSRGY} \\
& + \text { weight }_{\mathrm{PEP}} \times \text { Annaliued Average Return } \\
& \mathrm{PEP} \\
& + \text { weight }_{\mathrm{UL}} \times \text { Annaliued Average Return } \\
& + \text { weight }_{\mathrm{COKE}} \times \text { Annaliued Average Return } \\
& \mathrm{COKE}
\end{aligned}
$$

At the end, I settled some weights based on five constraints, and going to apply the portfolio under two different models, which are Index Model and Markowitz Model.

Index Model is a model to simplify analysis, the single-index model assumes that there is only 1 macroeconomic factor that causes the systematic risk affecting all stock returns and this factor can be represented by the rate of return on a market index, such as the SPX500.According to this model, the return of any stock can be decomposed into the expected excess return of the individual stock due to firm-specific factors, commonly denoted by its alpha coefficient, the return due to macroeconomic events that affect the market, and the unexpected microeconomic events that affect only the firm.

Except for Index model, I also consider Markowitz Model. The basic assumption of Markowitz Model theories are following these. Firstly, business risks are measurable, Enterprises with the same operating risk are at the same risk level. Secondly, now and future investors estimate exactly the same EBIT for the future, that is, investors' expectations of future earnings and the risks faced by these returns are consistent. Thirdly, the securities market is perfect, there are no transaction costs. Fourthly, investors can get loans at the same interest rate as the company. Fifthly, no matter how much debt is borrowed, Neither the Company nor the individual's liabilities are risky, Therefore, the liability interest rate is the risk-free interest rate. Sixth, Investor expected EBIT remains unchanged, that is, we assume that the enterprise growth rate is zero, thus all cash flows are annuities. Seventh, corporation's dividend policy is unrelated to corporate value, The issuance of new bonds does not affect the market value of existing debts.

Following are some constraints to build two models.

1.none(free)

There were no constraints.

$2 . \sum|w i| \leqq 2$

All weights sum up equal to two or smaller than two.

3. $\mid$ wi $\mid \leqq 1$ for all i

All weights absolute value are smaller than one or equal to one.

4.wi=0

The first weight is equal to zero. 
5.wi $\geqq 0$ for all $i$

All weights are bigger than zero or equal to zero.

\section{Result}

Then, there are some data compared between after covid-19 and before covid-19. First, I will compare the results before and after the covid 19 under Markowitz Model.

Table 2\&3: This is a table of Minimum variance and Maximum Sharpe ratio under the Markowitz Model before covid-19 and after covid-19.

TABLE 2. Minimum VARIANCE AND MAXIMUM SHARPE RATIO UNDER THE MARKOWITZ MODEL BEFORE COVID-19

\section{Before covid-19}

\section{MM}

Minimum variance

$\begin{array}{cccc} & \text { return } & \text { stdev } & \text { sharp } \\ 1 & 0.1232 & 0.1142 & 1.0787 \\ 2 & 0.1232 & 0.1022 & 1.2054 \\ 3 & 0.1232 & 0.1022 & 1.2054 \\ 4 & 0.1232 & 0.1123 & 1.0966 \\ 5 & 0.1232 & 0.1023 & 1.2045\end{array}$

Maximum Sharp ratio

\begin{tabular}{llll}
1 & 0.1232 & 0.1022 & 1.2054 \\
2 & 0.1232 & 0.1022 & 1.2054 \\
3 & 0.1232 & 0.1022 & 1.2054 \\
4 & 0.1232 & 0.1123 & 1.0966 \\
\hline
\end{tabular}

TABle 3. Minimum VARIANCE AND MAXIMUM SHARPE RATIO UNDER THE MARKOWITZ MODEL AFTER COVID-19

After covid-19

MM

Minimum variance

$\begin{array}{cccc} & \text { return } & \text { stdev } & \text { sharp } \\ 1 & 0.0410 & 0.1351 & 0.3034 \\ 2 & 0.0410 & 0.1350 & 0.3035 \\ 3 & 0.0410 & 0.1350 & 0.3035 \\ 4 & 0.0410 & 0.1350 & 0.3035 \\ 5 & 0.0488 & 0.1357 & 0.3597\end{array}$

Maximum Sharpe ratio

\begin{tabular}{llll}
1 & 0.2016 & 0.1992 & 1.0116 \\
2 & 0.2016 & 0.1992 & 1.0116 \\
3 & 0.2016 & 0.1992 & 1.0116 \\
4 & 0.2018 & 0.2840 & 0.7107 \\
\hline
\end{tabular}

Note: MM stands for Markowitz Model.

Under the Markowitz Model, beneath 5 constraints, I computed their minimal variance and Maximum Sharpe ratio.

First, it is the minimal variance, which is an index to show the rates of risk. If you have the bigger standard deviation, then portfolio had greater rates of risk. Before the covid-19, the standard deviation of minimal variance under the first constrain was the biggest, so the portfolio had the max risk rate when there was no constrains, under the second and third constrains had the same and the smallest 
standard variance, this meant beneath these two constrains the portfolio had the smallest risk rates; while after the covid-19, the standard deviation of minimal variance under the fifth constrains was the biggest, when all weights are bigger than zero or equal to zero the portfolio had the maximum risk rates, then came to the second, third and fourth, they shared the same standard deviation in the minimal variance, in this case, the portfolio had minimal risk rate.

Second, it is the Maximum Sharpe ratio, which is an index represent of the ratio of risk and return. If the rate is bigger than zero, then rate of return higher than rate of risk, if the rate is smaller than zero, then rate of return lower than rate of risk. Therefore, if the index much higher than zero, then this portfolio has great return and low risk. Before the covid-19, under the constrains of the weight of SPX500 is equal to zero had the least Maximum Sharpe ratio, which means under this constrains the portfolio should be least considered; while after the covid-19, the smallest Maximum Sharpe ratio still under the constraints of the fourth one. While before the covid-19, under the first, second and third constraints shared the same maximum Sharpe ratio; and after the covid-19, when under the constraints of all weights are bigger than zero or equal to zero, the maximum Sharpe ratio was the greatest.

Second, I will compare the results before and after the covid 19 under Index Model.

Table 4\&5: This is a table about Minimum variance and Maximum Sharpe ratio under the Index Model before covid-19 and after covid-19.

TABLE 4. Minimum VARIANCE AND MAXIMUM SHARPE RATIO UNDER THE INDEX MODEL BEFORE COVID-19

TABLE 5. MINIMUM VARIANCE AND MAXIMUM SHARPE RATIO UNDER THE INDEX MODEL AFTER COVID-19

\begin{tabular}{cccc}
\hline \hline After covid-19 & & & \\
\hline IM & & & \\
Minimum variance & return & stdev & sharp \\
1 & 0.0451 & 0.1199 & 0.3759 \\
2 & 0.0451 & 0.1199 & 0.3759 \\
3 & 0.0451 & 0.1199 & 0.3759 \\
4 & 0.0451 & 0.1199 & 0.3759 \\
5 & 0.0538 & 0.1208 & 0.4453 \\
Maximum Sharpe ratio & & & \\
1 & 0.1998 & 0.1971 & 1.0137 \\
3 & 0.1998 & 0.1971 & 1.0137 \\
4 & 0.1998 & 0.1971 & 1.0137 \\
\hline \hline
\end{tabular}


Note: IM stands for Index Model.

Under the Index Model, beneath 5 constraints, I computed their minimal variance and Maximum Sharpe ratio, too.

First, it is the minimal variance. Before the covid-19, the standard deviation of minimal variance under the first second third and fifth constrain shared the same biggest standard deviation, so the portfolio had the max risk rate when under these constrains, and in the same time, portfolio under the fourth constraints had the smallest standard variance, this meant beneath this constrains the portfolio had the smallest risk rates than others; while after the covid-19, the standard deviation of minimal variance under the fifth constrains was the biggest, when all weights are bigger than zero or equal to zero the portfolio had the maximum risk rates, then came to the third constraints, it's standard deviation was the smallest in the minimal variance, in this case, the portfolio had minimal risk rate.

Second, it is the Maximum Sharpe ratio. Before the covid-19, under the constrains the first weight is equal to zero had the least Maximum Sharpe ratio, which means under this constrains the portfolio should be least considered; while after the covid-19, the smallest Maximum Sharpe ratio still under the constraints of the fourth one. While before the covid-19, under the first second and third constraints shared the same maximum Sharpe ratio; and after the covid-19, when under all weights sum up equal to two or smaller than two the maximum Sharpe ratio was the greatest.

\section{Conclusion}

In this paper, I investigate the portfolio performance under two different models. The results suggest that the retail industry is preferred by investor if they have following transformation: (1) Change the retail model and promote unmanned distribution. During the epidemic period, due to the frequent contact of conventional logistics means, it reflected the disadvantages of excessive reliance on manpower and poor user experience. Promoting unmanned delivery, on the one hand, can reduce the contact between people, on the other hand, it can also speed up the transportation speed of goods, to give customers a better experience. (2) Pay attention to food healthy. The epidemic exposes the importance of food healthy, and it is expected that people will regain their attention to food healthy. Therefore, the topic about food healthy will inevitably be returned to the table in the future. (3) In addition, due to the epidemic impact of economic, it is predicted that people's consumption capacity will decline in the future for some time, and goods with low prices but good quality will be favored, but self-cleaning products always be considered selling at a premium. Therefore, retail enterprises can moderately strengthen the attention to goods with low prices but good quality and product cost performance in the future, so as to more adapt to the market. (4) Make good use of the golden period of "compensatory consumption" after the epidemic. After the epidemic fades, there will be 2 and 3 months of "compensatory consumption" time, and for companies who make full use of this period, their performance often rise up. Therefore, retail industries should make the most use of this time to improve the performance, like putting advertisement on the internet. (5) Reasonable arrangement of goods reserves. The hoarding wave and the subsequent purchase decline highlight the unreasonable goods reserves of some retail enterprises, such as the shortage of goods at the peak of the hoarding surge and the excess goods surplus in the purchase attenuation period. Therefore, the retail industry should improve its sensitivity to emergencies and reasonably allocate goods reserves to cope with the wave of hoarding and procurement attenuation following unconventional events.

\section{References}

[1] Z. Zhen, F.B. Wang., "Study on the negative impact mechanism and risk of COVID-19 epidemic on GVC embedding of Chinese manufacturing enterprises "Economic Theory and Business Management, vol.7, July 2020.

[2] W.F. Ye, "Challenges and countermeasures of the retail industry under COVID-19"Trade Fair Economy, vol 12, July 2020. 
[3] X.X. Lue, "Unmanned stores will become a trend in American retail?" Property Rights Guide, vol 03, March 2019.

[4] Z.J. Xu, "Analysis of the impact of the epidemic on the retail industry and the future development trend of the retail industry", Modern Business, vol 6,2021

[5] X. Guo, J. Xu, "on the high-quality development of China's retail industry after covid-19 is based on the concept model of "people, goods and field", "Science\& Technology and Economy", vol 03,2021.

[6] J.Y. Shen. "Refactoring its organizational structure and adjusting its product portfolio, Coca-Cola has entered a "new era" "Modern Advertisement, vol 19,2020

[7] S.B. Ma, Y.F. Zhang, "Brand marketing among the crowd under the epidemic" China Marketing, vol 04,2020

[8] Z. An, "Want instant noodles not to shampoo, the epidemic to rewrite the shopping list", Liberation Daily,2020.05.09.

[9] S.D. Nian, "Epidemic test: Which companies will be the "winners" "China Business Herald,2020.04.10

[10] J.J. Wang, Y.H. Guo, L.Y. Zhang, "The retail industry has accelerated changes", Qunzhong, vol 10,2020 